\title{
Effects of Weight-loss Knowledge, Attitude, and Motivation on Dietary Habits among College Students in their Twenties
}

Sol-Ah Kim, Eun-Kyung Sim*

Department of Beauty Care, Tongmyong University, Busan, Korea

\author{
*Corresponding author: Eun-Kyung Sim, \\ Department of Beauty Care, Tongmyong \\ University, 428 Sinseon-ro, Nam-gu, Busan \\ 48520, Korea \\ Tel.: +82 516292369 \\ Fax: +8251629 2019 \\ Email: 1118sim@hanmail.net
}

Received June 6, 2017

Revised October 12, 2017

Accepted October 30, 2017

Published March 30, 2018

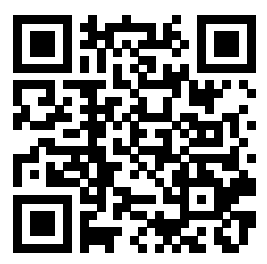

\begin{abstract}
Purpose: This study attempted to investigate the effects of weight-loss knowledge, attitude, and motivation on dietary habits among college students in their 20s. The goal is to help them have correct dietary habits and maintain a healthy lifestyle. In addition, this paper is targeted to provide basic data for an obesity control program. Methods: To examine the weight-loss knowledge, attitude, motivation, and dietary habits among young adults in their twenties, a self-administered questionnaire was conducted, and 267 questionnaires completed by youngsters from Gyeongsangnamdo, Busan, and Seoul were analyzed. Results: Participants with a high level of weight loss-related knowledge were highly interested in weight loss. They reported that they received information regarding weight loss through mass media and noted a lack of willpower and wrong dietary habits as the reasons for failing to achieve weight loss. Participants from the group that exhibited a statistically significant weight-loss attitude and motivation spent at least 100,000 KRW per month on weight loss, showed a high interest in weight loss, and received weight-loss-related information through mass media. In terms of dietary habits, the group that obtained information regarding weight loss through mass media, acquaintances, and weightrelated organizations displayed good dietary habits with a statistical significance. In addition, positive correlations were observed between weight loss attitude and motivation $(p<0.01)$. With regard to impact on dietary habits favoring weight loss, weight loss attitude was more relevant and influential than weight loss motivation and weight loss knowledge $(p<0.01)$. Conclusion: Weight-loss knowledge had no influence on dietary habits. As weight-loss attitude and motivation increased, better dietary habits were observed.
\end{abstract}

Keywords: Weight-loss knowledge, Attitude, Motivation, Dietary habits, College students

\section{Introduction}

세계보건기구(World Health Organization, WHO)는 1996 년 5월 16 일 ‘비만은 분명히 치료해야 하는 질병'으로 선언하였 으며 세계의 비만인구가 5 년마다 2 배씩 증가한다고 경고하였 다(Sim \& Lee, 2015). 우리나라도 서구적 생활습관과 외식의 증가 등 식습관의 변화로 인해 비만 유병률이 증가되고 있는 추 세로, 2014년 국민건강영양조사 결과에 따르면 만 30세 이상 성인의 비만 유병률은 $32.9 \%$ 로 조사되었다(KOSIS, 2016). 또 한, 아동 - 청소년 비만의 경우 약 1 조 3,638 억원의 사회경제적 비용이 유발되는 것으로 나타나(Lim et al., 2009), 노동생산
연령인 성장기의 청소년을 대상으로 한 적정한 정책개입을 통 해 과체중 또는 비만 청소년을 감소시킬 수 있다면 사회경제적 손실 중 상당 부분을 절감할 수 있는 효과를 달성할 수 있을 것 이다(Jung et al., 2010).

잘못된 생활과 식습관으로 발생되는 비만과 관련된 질환으 로는 당뇨, 암, 뇌혈관 질환, 고혈압 관련 질환, 관절증 등이 있 다. 특히 비만은 신체의 생리적 특성과 호르몬을 변화시켜 질 병의 상태를 바꿀 수 있는데, 이는 우리나라 10 대 사인 중에 1 위를 차지하는 암의 발생위험을 3 배 높이고 암환자의 생존율 을 낮추는 것과 관련되어 있다(Goodwin \& Stambolic, 2015). 비만은 지방간, 고혈압, 고지혈증, 심혈관 질환, 골관절염 등의 
발생요인으로 작용할 뿐 아니라 남성에 있어서는 전립선암, 대 장암, 직장암과 관련이 있고 여성에 있어서는 유방암, 자궁암, 난소암과 연관이 있으므로 여러 가지 만성 퇴행성 질환의 위 험요인이 될 수 있으므로 관심의 대상이 되고 있다(Na et al., 2008). 특히, 과체중과 비만은 폐경 후 여성들의 유방암, 결장 암, 직장암, 자궁내막, 식도와 신장의 선암종, 그리고 췌장암 을 포함한 많은 암의 발생을 증가시킬 뿐만 아니라(Protani et al., 2010), 암의 재발과 전체적인 사망률을 높이는 것으로 보 고되고 있다(Rock et al., 2012). 2007-2011년 동안 국민건강 영양조사에 참여한 유방암 생존자 125 명의 비만도를 평가하고 비만관련 요인인 신체활동도와 식이섭취 패턴을 확인하고자 실 시한 Seo et al. (2014)의 연구에 따르면, 한국인 유방암 생존 자 중 과체중 이상은 $67.4 \%$, 비만은 $48.4 \%$ 로 높은 비만율을 보였으며, 신체활동도는 낮았으며 지방 섭취는 낮았지만, 섬유 소 섭취도 낮은 것으로 조사되었다. 또 다른 연구결과로서 출 산 경험이 있는 40 세 이상인 유방암 환자는 비만 관리가 필요 한 것으로 조사되었다(Oh \& Hwang, 2017).

비만을 예방하기 위한 방법 중 하나로 운동을 생각할 수 있 는데, 전국 만 10 세 이상의 국민을 대상으로 7 개 광역시와 9 개 도의 동 지역, 읍/면 지역을 대상으로 한 2013 국민생활체육참 여실태조사 보고에 따르면, 규칙적 체육활동 참여 여부와 빈도 에 대한 조사결과에서 '전혀 하지 않는다'는 응답이 $41.8 \%$, '주 1회' (14.1\%), '한 달에 2-3번 정도' (12.7\%), '주 3회' (10.1\%), '주 2회' (8.8\%) 등의 순으로 응답하였다(Ministry of Culture, Sports and Tourism, 2012). 이와 같이 운동을 하는 비율이 저조하다 보니 대학생은 $22.4 \%$ 가 과체중으로, $19.2 \%$ 가 비만 으로 나타나(Ahn et al., 2014), 학교나 지역사회에서 아동 . 청소년을 대상으로 신체활동에 대한 인식의 변화와 정보를 제 공하고 이를 실천에 옮길 수 있는 전략이 절실하다(Yoo \& Lee, 2017).

또한 비만을 예방 및 관리하기 위해 필수적으로 알아야 할 영양에 대한 객관적 지식과 식습관의 관계는 건강한 삶을 영위 하기 위한 필수 불가결한 조건이라고 할 수 있다(Choi \& Kim, 2012). 대학입시라는 많은 스트레스를 겪은 후 맞이하게 되는 청소년기의 끝이자 성인기에 속해 있는 생산연령인구인 대학생 들의 건강은 향후 국가 경쟁력에 영향을 미치는 중요한 사안임 을 간과해서는 안 될 것이라 생각한다.

고등학교 시절의 획일화된 생활과 부모의 통제를 벗어난 대 학생들은 장거리 통학이나 기숙사 생활, 특히 자취생들은 자 신의 생활을 독립적으로 관리하게 되는데 제한된 경제력, 불 규칙한 수업시간, 그릇된 영양지식 등으로 영양적 측면보다 는 기호에 우선하여 음식을 선택하는 등 식생활에 소홀해지기 쉬우며 영양불량 상태를 초래할 우려도 있는 것으로 나타났다 (Beerman, 1991; Han \& Cho, 1998). 그러므로 20대 초반인
대학시절에 바람직한 식습관의 기틀을 확실하게 잡도록 하는 것은 무엇보다도 중요한 일이다. 그러나 최근에는 대중매체의 발달로 건강보다는 외모에 지나치게 관심이 증대됨에 따라 사 회적으로 많은 문제점이 야기되고 있다(Lee \& Kwak, 2006). 또한 현대의 영상 - 광고매체, 패션, 미용산업과 다이어트 산업 군에서 외모의 중요성을 지나치게 강조함으로써 날씬하다 못해 영양불량의 마른 몸매에 대해 선호하게 되는 다이어트 집착에 대한 성향이 여자 대학생 사이에서 당연하게 생각되고 있다. 건강체중에 대한 사회적인 편견에 의해 정상체중인 사람들도 미용목적으로 체중조절에 대한 관심이 고조되면서 비만관련 산 업은 급속도로 팽창하였으며 특히 1990년대 이후 인터넷의 보 급으로 비만산업은 큰 전환점을 맞이하게 되었다(Yim, 2003).

대학생 시기의 올바른 식습관 확립 및 균형 잡힌 식품 섭취 를 통해 건강한 생활을 영위할 수 있도록 학교나 지역 사회 및 정부 차원에서 지속적이고 체계적인 영양 교육이 필요하다. 또 한 일단 성립된 바람직하지 않은 식습관은 쉽게 변화하지 않으 므로 이론 위주의 영양 교육보다는 실제적인 행동변화를 유도 할 수 있는 적극적인 영양 교육 프로그램이 필요하다. 바람직 한 식생활 영위를 위해서 영양소 및 식품에 관한 지식을 전달하 는 것뿐만 아니라, 영양적으로 균형 잡힌 식사를 하려는 적극 적인 태도 및 실천 의욕을 고취시키고 그 점을 개선하고자 하는 식행동으로 변화를 유도할 수 있는 영양 교육의 기회 부여가 절 실히 필요하다고 사료된다(Kang et al., 2013).

따라서 본 연구를 통해서 20 대들이 실제 보유하고 있는 다이 어트 지식, 태도, 동기를 파악하여 이를 통하여 다이어트 식습 관과의 상호 영향을 조사하여 올바른 다이어트 방법을 통한 건 강한 다이어트를 하게 하는 것을 목적으로 할 뿐 아니라 건강한 생활유지에 도움을 주고자 한다.

\section{Methods}

\section{1. 연구대상 및 기간}

본 연구의 조사대상은 경상남도, 부산, 서울 지역의 20 대 남 녀 300명을 대상으로 2016년 3월 7일부터 3월26일까지 총 300 부의 설문지를 배부하여 280 부를 회수하였고, 그 중 불성 실응답지 13 부를 제외한 267 부를 분석에 이용하였다.

\section{2. 설문지의 구성}

연구에 사용된 설문지는 선행 연구자들에 의하여 개발된 항 목을 본 연구에 맞춰 수정, 보완하였으며 연구대상자에게 연구 의 목적을 설명하고 직접 기록하게 하는 자기 기입식 기록방법 을 이용하였다. 설문지의 내용은 조사대상자인 20 대의 다이어 트 지식, 다이어트 태도, 다이어트 동기 및 식습관에 관한 항목 
으로 구성되었으며 Table 1과 같다.

\section{1) 다이어트 지식}

다이어트 지식에 관한 문항은 Choe et al. (1999)의 연구를 기초로, 본 연구의 응답자 특성을 고려하여 재구성하였다. 이 를 토대로 조사대상자가 다이어트에 관한 지식을 얼마나 알고 있는지를 알아보기 위하여 비만의 원인, 식사속도, 흡연여부, 질환과 연관성, 운동행동으로 구성하여 총 15 문항으로 구성하 였다. 문항에 대하여 정답은 1 점, 오답은 0 점 처리하여 사용하 였다.

\section{2) 다이어트 태도}

다이어트 태도에 관한 문항은 선행연구(Choe et al., 1999; Choi et al., 2004)를 기초로 하여 본 연구에 맞게 재구성하였 다. 조사대상자가 다이어트에 관해 어떤 태도를 가지고 있는지 를 알아보기 위하여 다이어트의 필요성, 자아인식, 정보 및 교 육, 실행으로 구성하여 총 9 문항으로 구성하였다.

\section{3) 다이어트 동기}

남성에 비해 여성이 자신의 신체에 대해 불만족하는 성향은 대중매체 및 사회 · 문화적 선입견에서 야기된 것이고 신체불만 족 수준이 증가할수록 섭식장애 습관이 발생하는 경향이 있다 (Stice \& Shaw, 2002). Kim \& Lee (2006)의 연구에서도 연 령별로 아름다워 보이기 위한 목적으로 다이어트 하는 것은 20 대가 연구대상자의 $73 \%$ 로 가장 높게 조사되었다. 또한 자기존 중감과 다이어트 의식의 관계를 살펴 볼 때, 다이어트의 큰 동 기가 자신의 건강과 외모에 대한 이유 때문이라고 답한 사람이 많은데, 이는 사회적인 이슈가 되고 있는 웰빙과 외모에 대한 관심이 날로 증가하고 있기 때문이라고 생각된다(Na \& Jang, 2007).

다이어트 동기에 관한 문항은 다이어트 시 동기가 되는 요 인을 알아보기 위하여 Lee et al. (2015)의 논문을 참조하여 건 강, 자신감, 활동성, 옷 선택, 식비절감, 외모, 호의적 태도, 이 성, 취업으로 구성하여 총 9 문항으로 재구성하였다.
4) 식습관

습관은 거의 무의식적으로 행해지며 선천적이기보다는 후천 적인 행동을 가리킨다. 먹고 자는 것에서부터 생각하고 반응하 는 것에 이르기까지 어떤 행동이든 습관이 될 수 있다. 개인의 식생활 습관은 좀처럼 변화하기 어려운 보수적인 것이나 사회 전반적인 요인으로부터 직접, 간접적인 영향을 받게 된다(Park et al., 2010).

식습관에 관한 문항은 선행연구(Kim et al., 1992; Lee, 2009; Park et al., 2010)를 기초로 하여 본 연구의 목적에 맞 추어 편식, 결식, 식사량, 야식, 폭식, 선호도로 구성하여 총 10 문항으로 구성하였다.

\section{3. 자료 처리}

자료의 분석 방법으로는 통계 패키지 Statistical Package for the Social Sciences (SPSS 18.0; IBM, USA) 프로그램 을 이용하였다. 리커트(Likert)식 4점 척도방법을 이용하여 조 사대상자의 다이어트에 대한 지식, 태도, 동기 및 식습관을 측 정하였다. 사회 인구학적 특성 및 다이어트 특성에 따른 다이 어트 지식, 태도, 동기 및 식습관의 차이를 분석하기 위해서 $t$-test 및 analysis of variance (ANOVA) 분석을 실시하였다. 또한 독립변수인 다이어트 지식, 태도, 동기와 식습관의 관련 성을 검정하기 위해 상관관계분석을 실시하였으며, 식습관에 영향을 미치는 요인을 검정하기 위해 다이어트 지식, 태도, 동 기를 설명변수로 하는 단회귀분석을 실시하였다. 유의수준 $(p)$ 는 0.05 로 설정하였다.

\section{Results and Discussion}

\section{1. 대상자의 다이어트 특성}

조사대상자의 다이어트 관련 특성을 파악하기 위해 빈도분석 을 실시하였으며 결과는 Table 2 와 같다. 다이어트 지출비용에 는 10 만원 미만 209 명(78.3\%), 다이어트 경험에서는 5회 이상 이 94 명(35.2\%)으로 가장 많았으며, 2 회가 62 명(23.2\%)으로 조사되었다. 다이어트 관심도에서는 관심이 있다고 응답한 사 람이 185 명 $69.3 \%)$ 로 가장 많았으며, 관심이 없다고 응답한 사

Table 1. Questionnaire design

\begin{tabular}{|c|c|c|}
\hline Variable & Description & $\begin{array}{l}\text { Number of } \\
\text { questions }\end{array}$ \\
\hline Weight-loss knowledge & Causes of obesity, pace of eating, smoking status, relevance to diseases, exercise behavior & 15 \\
\hline Weight-loss attitude & Necessity, self-recognition, information and education, execution & 9 \\
\hline Weight-loss motivation & $\begin{array}{l}\text { Health, confidence, activity, selection of clothing, decrease in food expenses, appearance, } \\
\text { favorable attitude, opposite sex, employment }\end{array}$ & 9 \\
\hline Dietary habits & Picky eating, skipping meals, eating capacity, night eating, binge eating, preferences & 10 \\
\hline
\end{tabular}


람은 20 명 $(7.5 \%)$ 으로 소수에 불과하였다. 다이어트에 영향을 준 사람으로는 나 자신이 164 명(61.4\%)으로 과반수 이상을 차 지하였으며, 다음이 이성친구/배우자/가족이 71명(26.6\%)으로 나타났다. 다이어트 정보 유입 경로로는 미디어 매체가 177명 (66.3\%)로 가장 많았고, 다음으로 주변 사람들이 59명(22.1\%) 이었다. 이는 대전 대학생을 대상으로 한 Kim et al. (2010)의 연구에서도 대학생들이 인터넷에서 다이어트 관련된 정보를 얻 는 것으로 조사된 것과 동일하였다.

다이어트 실패원인으로는 의지력 부족이 204 명(76.4\%)으 로 가장 많았고, 잘못된 식습관 51 명(19.1\%), 기타사유 12 명 (4.5\%)의 순으로 조사되었다. 그리고 조사대상자가 주로 이용 하는 다이어트 방법은 1순위에서는 신체운동이 147명(55.0\%) 으로 가장 많았고, 2순위에는 식사조절이 104명(39.0\%), 3순 위는 보조식품섭취 16 명(6.0\%)의 비율로 나타났다. 다이어트 방법으로 Jung (2004)의 연구에서 대학생 응답자 40\%가 체중 조절을 해온 것과 유사하게 본 연구 결과에서도 운동과 식이요 법을 가장 선호한 것으로 조사되었다.

\section{2. 다이어트 특성에 따른 지식, 태도, 동기 및 식습관}

다이어트 특성별 다이어트 지식, 태도, 동기 및 식습관의 변 이를 검정하기 위해 $t$-test, ANOVA를 실시한 결과는 Table 3 와 같다. 분석 결과를 살펴보면, 다이어트 특성별 다이어트 지 식의 변이에서는 다이어트 관심도, 정보유입경로, 실패원인에 따라 통계적으로 유의한 차이를 보였다. 즉, 다이어트 관심도 가 높을수록, 정보유입경로는 미디어가 다이어트 관련 전문기 관에 비해, 실패원인은 의지력 부족과 잘못된 식습관이라 응답 한 그룹이 다른 그룹에 비해 다이어트 지식 수준이 높았다. 다 이어트 태도에서는 다이어트 지출비용, 경험, 관심도, 정보유 입경로, 실패원인에서 통계적으로 유의한 차이를 보였는데, 다 이어트 지출비용은 10 만원 이상, 경험 횟수가 많을수록, 관심 도가 높을수록, 정보유입경로는 미디어라 응답한 그룹, 실패원 인으로 기타사유라고 한 그룹이 다이어트 태도 수준이 유의하 게 높았다. 다이어트 동기에서도 다이어트 지출비용, 관심도, 정보유입경로, 실패원인에서 통계적으로 유의한 차이를 보였는 데, 다이어트 지출비용은 10 만원 이상, 관심도는 높을수록, 정 보유입경로는 주변 사람들과 미디어라고 응답한 그룹, 실패원

\section{Table 2. Characteristics of weight-loss}

\begin{tabular}{|c|c|c|c|}
\hline Variable & Category & Frequency & Percentage \\
\hline \multirow{2}{*}{ Amount of money spent for weight-loss in a month } & Less than KRW 100,000 & 209 & 78.3 \\
\hline & KRW 100,000 or more & 58 & 21.7 \\
\hline \multirow{5}{*}{ Weight-loss experience } & Once & 41 & 15.4 \\
\hline & Twice & 62 & 23.2 \\
\hline & 3 times & 42 & 15.7 \\
\hline & 4 times & 28 & 10.5 \\
\hline & 5 times or more & 94 & 35.2 \\
\hline \multirow{3}{*}{ Interest in weight-loss } & Uninterested & 20 & 7.5 \\
\hline & Neither interested or uninterested & 62 & 23.2 \\
\hline & Interested & 185 & 69.3 \\
\hline \multirow{3}{*}{ Who made you start weight-loss } & $\mathrm{Me}$ & 164 & 61.4 \\
\hline & Friend (opposite sex), spouse, family & 71 & 26.6 \\
\hline & Colleague, coworker, friend (same sex) & 32 & 12.0 \\
\hline \multirow{4}{*}{ Weight-loss information acquisition channel } & Mass media & 177 & 66.3 \\
\hline & Acquaintance & 59 & 22.1 \\
\hline & Weight-loss related organization & 13 & 4.9 \\
\hline & Etc. & 18 & 6.7 \\
\hline \multirow{3}{*}{ Causes of weight-loss failure } & Lack of willpower & 204 & 76.4 \\
\hline & Wrong dietary habits & 51 & 19.1 \\
\hline & Etc. & 12 & 4.5 \\
\hline \multirow{3}{*}{ Primary weight-loss method } & Physical exercise & 147 & 55.0 \\
\hline & Diet & 104 & 39.0 \\
\hline & Healthy supplement & 16 & 6.0 \\
\hline Total & & 267 & 100.0 \\
\hline
\end{tabular}


인으로 기타사유라 응답한 그룹이 다이어트 동기가 유의하게 높았다. 식습관에서는 다이어트 정보유입경로에서 통계적으로 유의한 차이를 보였고, 사후 검정결과 미디어, 주변 사람들, 다 이어트 관련 전문기관이라 응답한 그룹이 기타사유 그룹에 비 해 식습관이 유의하게 좋았다.

\section{3. 다이어트 지식, 태도, 동기 및 식습관의 상관관계}

본 연구의 다이어트 지식, 태도, 동기 및 식습관 간의 관련성 을 검정하기 위해 상관관계분석을 실시한 결과는 Table 4 와 같 다. 분석 결과, 식습관은 다이어트 태도, 다이어트 동기와 통 계적으로 유의한 부(-)의 관련성을 보이는 것으로 나타났으며 $(p<0.01)$, 다이어트 태도가 다이어트 동기보다 식습관과의 더 유의한 관련성을 보였다. 또한, 다이어트 태도와 다이어트 동
기는 정 $(+)$ 의 상관관계를 보였다 $(p<0.01)$.

\section{4. 식습관에 영향을 미치는 요인}

식습관에 영향을 미치는 요인을 검정하기 위해 다이어트 지 식, 태도, 동기를 설명변수로 하는 단회귀분석을 실시하였다.

\section{1) 다이어트 지식이 식습관에 미치는 영향}

다이어트 지식이 식습관에 미치는 영향을 파악하기 위해 단 회귀분석을 실시한 결과, 다이어트 지식은 식습관에 영향을 미 치지 않았다(Table 5). 본 연구의 결과는 영양지식점수가 우수 한 학생이 식습관에서 바람직하지 못한 지식과 행동을 나타냈 다는 선행연구(Joo, 2017; Kim et al., 2013)와 비슷한 결과를 보였다. 또한 대학생을 대상으로 한 Park \& Kwon (2012)의 연

Table 3. Weight-loss knowledge, attitude, motivation, and dietary habits by weight-loss characteristics

Unit: M (S.D.)

\begin{tabular}{|c|c|c|c|c|c|}
\hline Variable & Category & Knowledge & Attitude & Motivation & Dietary habits \\
\hline \multirow{3}{*}{$\begin{array}{l}\text { Amount of money } \\
\text { spent for weight-loss }\end{array}$} & $\begin{array}{l}\text { Less than KRW } \\
100,000\end{array}$ & $9.71(2.63)$ & $2.91(0.41)$ & $3.14(0.40)$ & $2.36(0.42)$ \\
\hline & $\begin{array}{l}\text { KRW } 100,000 \text { or } \\
\text { more }\end{array}$ & $9.54(2.63)$ & $3.07(0.37)$ & $3.31(0.37)$ & $2.31(0.38)$ \\
\hline & $t(p)$ & $0.435(0.664)$ & $-2.513(0.013)$ & $-2.822(0.005)$ & $0.755(0.451)$ \\
\hline \multirow{6}{*}{$\begin{array}{l}\text { Weight-loss } \\
\text { experience }\end{array}$} & Once & $9.83(2.29)$ & $2.85(0.33)$ & $3.10(0.30)$ & $2.33(0.43)$ \\
\hline & Twice & $9.47(2.82)$ & $2.85(0.44)$ & $3.10(0.48)$ & $2.38(0.46)$ \\
\hline & 3 times & $9.48(2.59)$ & $2.96(0.39)$ & $3.14(0.35)$ & $2.39(0.35)$ \\
\hline & 4 times & $9.92(2.17)$ & $3.03(0.35)$ & $3.24(0.41)$ & $2.37(0.35)$ \\
\hline & 5 times or more & $9.80(2.78)$ & $3.02(0.41)$ & $3.25(0.39)$ & $2.33(0.43)$ \\
\hline & $F(p)$ & $0.296(0.88)$ & $2.685(0.032)$ & $2.002(0.095)$ & $0.297(0.880)$ \\
\hline \multirow{4}{*}{$\begin{array}{l}\text { Interest in weight- } \\
\text { loss }\end{array}$} & Uninterested & $7.40(3.23)^{a}$ & $2.80(0.33)^{a}$ & $3.02(0.45)^{a}$ & $2.38(0.50)$ \\
\hline & $\begin{array}{l}\text { Neither interested or } \\
\text { uninterested }\end{array}$ & $9.83(2.64)^{b}$ & $2.83(0.33)^{\mathrm{ab}}$ & $3.07(0.31)^{a b}$ & $2.37(0.37)$ \\
\hline & Interested & $9.84(2.47)^{b}$ & $3.00(0.43)^{b}$ & $3.22(0.41)^{b}$ & $2.34(0.42)$ \\
\hline & $F(p)$ & $8.305(0.000)$ & $5.125(0.007)$ & $4.894(0.008)$ & $0.205(0.815)$ \\
\hline \multirow{4}{*}{$\begin{array}{l}\text { Who made you start } \\
\text { weight-loss }\end{array}$} & $\mathrm{Me}$ & $9.77(2.52)$ & $2.93(0.37)$ & $3.17(0.36)$ & $2.36(0.41)$ \\
\hline & $\begin{array}{l}\text { Friend (opposite } \\
\text { sex), spouse, family }\end{array}$ & $9.18(2.91)$ & $2.93(0.40)$ & $3.16(0.40)$ & $2.37(0.39)$ \\
\hline & $\begin{array}{l}\text { Colleague, coworker, } \\
\text { friend (same sex) }\end{array}$ & $10.22(2.46)$ & $3.04(0.57)$ & $3.25(0.57)$ & $2.28(0.50)$ \\
\hline & $F(p)$ & $2.029(0.133)$ & $1.037(0.356)$ & $0.648(0.524)$ & $0.574(0.564)$ \\
\hline \multirow{5}{*}{$\begin{array}{l}\text { Weight-loss } \\
\text { information } \\
\text { acquisition channel }\end{array}$} & Mass media & $10.09(2.37)^{b}$ & $2.98(0.37)^{b}$ & $3.20(0.35)^{b}$ & $2.34(0.39)^{\mathrm{a}}$ \\
\hline & Acquaintance & $9.02(2.83)^{\mathrm{ab}}$ & $2.95(0.47)^{\mathrm{ab}}$ & $3.21(0.51)^{b}$ & $2.31(0.48)^{a}$ \\
\hline & $\begin{array}{l}\text { Weight-loss related } \\
\text { organization }\end{array}$ & $7.73(2.80)^{a}$ & $2.79(0.54)^{\mathrm{ab}}$ & $2.84(0.39)^{a}$ & $2.28(0.40)^{a}$ \\
\hline & Etc. & $9.06(3.35)^{\mathrm{ab}}$ & $2.72(0.34)^{a}$ & $3.03(0.37)^{\mathrm{ab}}$ & $2.61(0.41)^{b}$ \\
\hline & $F(p)$ & $5.269(0.002)$ & $2.919(0.035)$ & $3.724(0.012)$ & $2.789(0.041)$ \\
\hline \multirow{4}{*}{$\begin{array}{l}\text { Causes of weight- } \\
\text { loss failure }\end{array}$} & Lack of willpower & $10.07(2.36)^{b}$ & $2.91(0.40)^{a}$ & $3.14(0.40)$ & $2.35(0.40)$ \\
\hline & Wrong dietary habits & $9.14(2.51)^{b}$ & $2.96(0.35)^{a}$ & $3.24(0.38)$ & $2.29(0.35)$ \\
\hline & Etc. & $7.71(3.29)^{\mathrm{a}}$ & $3.14(0.42)^{b}$ & $3.32(0.43)$ & $2.41(0.54)$ \\
\hline & $F(p)$ & $13.812(0.000)$ & $5.041(0.007)$ & $3.207(0.042)$ & 0.717 (0.489) \\
\hline
\end{tabular}

$\dagger^{\mathrm{a}}$ and ${ }^{\mathrm{b}}$ refer to subgroups at a 0.05 significance level where Duncan's post hoc test was performed.

$\mathrm{M}$, mean; S.D., standard deviation. 
구에서도 암 관련 지식과 암 예방 건강행위지식과 실천행위가 연관성이 없음으로 나타났다.

이와 반대로 초등학생의 식생활 교육 프로그램이 식습관 향 상에 도움을 주었다는 Choi \& Ryu (2010)의 연구와 대학생을 대상으로 한 객관적, 주관적인 영양지식이 식습관에 직접적인 영향을 미치는 것으로 나타난 Choi \& Kim (2012) 연구도 있어 다이어트지식 관련 설문지 개발의 필요성을 확인하였다.

\section{2) 다이어트 태도가 식습관에 미치는 영향}

다이어트 태도가 식습관에 미치는 영향을 파악하기 위해 단 회귀분석을 실시한 결과, 다이어트 태도는 식습관에 부(-)의 영향을 미치는 것으로 나타났다(Table 6). 즉, 다이어트에 대한 태도 수준이 높을수록 좋은 식습관을 가진다는 의미이다. 모형 내의 설명변수의 설명력은 $4.8 \%$ 이며, 회귀모형은 통계적으로 유의하였다 $(F=13.184 ; p=0.000)$.
3) 다이어트 동기가 식습관에 미치는 영향

다이어트 동기가 식습관에 미치는 영향을 파악하기 위해 단 회귀분석을 실시한 결과, 다이어트 동기는 식습관에 부(-)의 영향을 미치는 것으로 나타났다(Table 7). 즉, 다이어트 동기가 높을수록 좋은 식습관을 가진다는 의미이다. 또한, 모형내의 설명변수의 설명력은 $4.3 \%$ 이며, 회귀모형은 통계적으로 유의 하였다 $(F=11.695 ; p=0.001)$.

\section{Conclusion}

본 연구는 경상남도, 부산, 서울 지역에 거주하고 있는 20 대 남녀 대학생 267 명을 대상으로 다이어트 지식, 태도, 동기를 조사하여 식습관에 미치는 영향을 확인함으로써 올바른 식습관 형성에 도움을 주는 기초자료를 제공하는데 목적을 두고 있다. 연구 결과는 다음과 같다.

Table 4. Correlations among weight-loss knowledge, attitude, motivation, and dietary habits

\begin{tabular}{|c|c|c|c|c|}
\hline Variable & Knowledge & Attitude & Motivation & Dietary habits \\
\hline Attitude & 0.082 & & & \\
\hline Motivation & 0.108 & $0.578^{* *}$ & & \\
\hline Dietary habits & -0.049 & $-0.218^{* *}$ & $-0.207^{* *}$ & \\
\hline
\end{tabular}

${ }^{* *} p<0.01$.

Table 5. Effects of weight-loss knowledge on dietary habits

\begin{tabular}{lrrrr}
\hline Variable & $\mathrm{B}$ & $\beta$ & $t$ & $p$ \\
(Constant) & 2.426 & & 24.945 & 0.000 \\
Total & -0.008 & -0.049 & -0.799 & 0.425 \\
$\mathrm{R}^{2}=0.002$ & Adj. $\mathrm{R}^{2}=-0.001$ & $F=0.638$ & $p=0.425$ & \\
\hline
\end{tabular}

$\mathrm{B}$, unstandardized coefficient; $\beta$, standardized coefficient; $t$, $t$-test; $\mathrm{R}^{2}$, coefficient of determination; Adj. $\mathrm{R}^{2}$, adjusted coefficient of determination; $F, F$-value; $p, p$-value.

\section{Table 6. Effects of weight-loss attitude on dietary habits}

\begin{tabular}{lrrrr}
\hline Variable & $\mathrm{B}$ & $\beta$ & $t$ & $p$ \\
(Constant) & 3.012 & & 16.412 & 0.000 \\
Total & -0.224 & -0.218 & -3.631 & 0.000 \\
$\mathrm{R}^{2}=0.048$ & Adj. $\mathrm{R}^{2}=0.044$ & $F=13.184$ & $p=0.000$ & \\
\hline
\end{tabular}

$\mathrm{B}$, unstandardized coefficient; $\beta$, standardized coefficient; $t, t$-test; $\mathrm{R}^{2}$, coefficient of determination; Adj. $\mathrm{R}^{2}$, adjusted coefficient of determination; $F, F$-value; $p, p$-value.

Table 7. Effects of weight-loss motivation on dietary habits

\begin{tabular}{lrrrc}
\hline Variable & $\mathrm{B}$ & $\beta$ & $t$ & $p$ \\
(Constant) & 3.029 & & 15.160 & 0.000 \\
Total & -0.213 & -0.207 & -3.420 & 0.001 \\
$\mathrm{R}^{2}=0.043$ & Adj. $\mathrm{R}^{2}=0.039$ & $F=11.695$ & $p=0.001$ & \\
\hline
\end{tabular}

$\mathrm{B}$, unstandardized coefficient; $\beta$, standardized coefficient; $t, t$-test; $\mathrm{R}^{2}$, coefficient of determination; Adj. $\mathrm{R}^{2}$, adjusted coefficient of determination; $F, F$-value; $p, p$-value. 
1. 조사대상자의 다이어트 관련 특성을 파악하기 위한 분석 결과, 다이어트 관련 지출비용은 10 만원 미만(78.3\%), 다이어 트 경험은 5 회 이상(35.2\%)이었다. 그리고 다이어트에 관심이 있다고 응답한 사람은 $69.3 \%$ 인 반면, 다이어트에 관심이 없다 고 응답한 사람은 $7.5 \%$ 로 소수에 불과했다는 점을 미루어 봤을 때 20 대 조사대상자의 대부분이 다이어트에 관심이 있으며 다 이어트 경험이 많은 것으로 조사되었다.

2. 다이어트에 영향을 준 사람으로는 나 자신이라고 응답한 사람이 $61.4 \%$ 로 전체 조사대상자의 과반수 이상을 차지하는 것으로 보아, 체중조절을 시도하는 이유로서 자신의 체형에 만 족하지 못하기 때문이라고 볼 수 있다.

3 . 다이어트 정보 유입 경로는 20 대 대학생들로서 미디어 매 체를 통한 정보습득이 177 명(66.3\%)으로 가장 많았고, 다음으 로 주변 사람들이 59 명(22.1\%)이었다. 또한 다이어트 실패원인 으로는 의지력 부족이 204명(76.4\%)으로 가장 많았고, 잘못된 식습관 51 명(19.1\%)의 순으로 조사되었다.

4. 다이어트 방법에 있어서는 주로 이용하는 방법의 1순위 신체운동, 2순위 식사조절, 3순위 보조식품 순서로 조사되었 다. 조사대상자 대부분이 20 대 초반이었으며 한 달 다이어트 관련 지출비용이 10 만원 미만이 가장 많았던 결과로 보아 20 대 들은 다이어트 방법을 택하는 데 있어서 비용적 부담이 적은 방 법을 선호하는 것을 알 수 있다.

5. 다이어트 특성별 다이어트 지식의 변이에서는 다이어트 관심도, 정보유입경로, 실패원인에 따라 통계적으로 유의한 차 이를 보였다. 즉, 다이어트 관심도가 높을수록, 정보유입경로 는 미디어가 다이어트 관련 전문기관에 비해, 실패원인은 의지 력 부족과 잘못된 식습관이라 응답한 그룹이 다른 그룹에 비해 다이어트 지식 수준이 높았다.

6. 다이어트 태도에서는 다이어트 지출비용, 경험, 관심도, 정보유입경로, 실패원인에서 통계적으로 유의한 차이를 보였는 데, 다이어트 지출비용은 10 만원 이상, 경험 횟수가 많을수록, 다이어트 관심도가 높을수록, 정보유입경로는 미디어라 응답한 그룹, 실패원인으로 기타사유라고 한 그룹이 다이어트 태도 수 준이 유의하게 높았다.

7. 다이어트 동기에서도 다이어트 지출비용, 관심도, 정보유 입경로, 실패원인에서 통계적으로 유의한 차이를 보였는데, 다 이어트 비용은 10 만원 이상, 다이어트 관심도는 높을수록, 정 보유입경로는 주변 사람들과 미디어라고 응답한 그룹, 실패원 인으로 기타사유라 응답한 그룹이 다이어트 동기가 유의하게 높았다.

8. 식습관에서는 다이어트 정보유입경로에서 통계적으로 유 의한 차이를 보였고, 사후 검정결과 미디어, 주변 사람들, 다이 어트 관련 전문기관이라 응답한 그룹이 기타사유 그룹에 비해 식습관이 유의하게 좋았다.
9. 다이어트 지식은 식습관에 영향을 미치지 않은 것으로 조 사되었고 다이어트 태도 즉, 다이어트 필요성, 자아인식, 정보 및 교육, 실행 등이 좋을수록 좋은 식습관을 가진다고 분석되 었다. 다이어트 동기 즉, 건강, 자신감, 활동성, 옷 선택, 식비 절감 등의 동기가 높을수록 좋은 식습관을 갖는 것으로 나타났 다.

10. 다이어트 지식은 식습관에 유의한 관련성을 갖지 않으며 다이어트 태도 및 동기가 유의한 관련성을 가지는 것으로 분석 되었고, 특히 다이어트 동기보다 다이어트 태도가 식습관에 더 유의한 관련성을 가지는 것으로 분석되었다.

본 연구를 통하여 20 대 대학생의 영양지식이 실제적으로 올 바른 식습관에 영향을 주지 않는 것으로 조사된바 이론 위주의 영양 교육에서 보다 더 현실적이고 실천적인 식습관의 행동변 화를 유도할 수 있는 관련 교양교과목이 필요하다고 사료된다. 또한 건전한 자아인식을 고취시키고, 적절하고 균형 잡힌 다이 어트 필요성, 올바른 정보 및 교육 프로그램을 제공하여 실행 할 수 있도록 하여야겠다.

외모에 많은 신경을 쓰게 되는 20대 남녀 대학생들은 사회적 으로 생산연령인구에 속하는 집단으로서 보다 건강한 식습관 을 통해 건강을 유지해야 한다고 생각한다. 균형 잡힌 식습관 을 통해 적절한 체중관리를 함으로써 건강을 유지하기 위해 지 속적인 영양 교육과 사회적으로 건강한 체형에 대한 인식의 변 화 및 분위기 조성이 필요한 것으로 사료된다.

\section{References}

Ahn MY, Lee JJ, Oh HS, Lim HH. Effect of BMI, blood parameters and life pattern on KOQOL in health checkup examinees of college students. Journal of Oriental Rehabilitation Medicine, 24: 71-82, 2014.

Beerman KA. Variation in nutrient intake of college students: a comparison by students' residence. Journal of the American Dietetic Association, 91: 343-344, 1991.

Choe EO, Woo KJ, Chyun JH. Perception and knowledge on the diet among women living in Inchon. Journal of the Korean Society of Food Culture, 14: 225-231, 1999.

Choi JE, Kim YG. The relationship between university students' nutrition knowledge, dietary self-efficacy, dietary habits and menu choice behavior. Journal of Foodservice Management, 15: 249-275, 2012.

Choi JG, Shin MK, Seo ES. A study on self-evaluated obesity and food habits by residence type of college students in Ik-San area. Korean Journal of Human Ecology, 13: 97- 
110, 2004.

Choi JY, Ryu SH. Effect of the dietary life education program on elementary school students' nutrition knowledge and eating habit. Journal of Korean Practical Arts Education, 23: 319-334, 2010.

Goodwin PJ, Stambolic V. Impact of the obesity epidemic on cancer. Annual Review of Medicine, 66: 281-296, 2015.

Han MJ, Cho HA. Dietary habit and perceived stress of college students in Seoul area. Journal of the Korean Society of Food Culture, 13: 317-326, 1998.

Joo BH. Analysis of relationship between understanding level on knowledge of health and health behavior practice. The Journal of Korea Society for Wellness, 12: 475-487, 2017.

Jung DJ. A study on the recognitions for the obesity and attitudes toward the eating habit and the weight control behaviors of university students in Cheongju province. Journal of Science \& Culture, 1: 1-8, 2004.

Jung YH, Ko S, Lim HJ. The Socioeconomic cost of adolescent obesity. Health and Social Welfare Review, 30: 195-219, 2010.

Kang JE, Choi HS, Choi JH, Jung ST, Yeo SH, Kim MH. The comparative study of dietary habits according to the alcohol drinking among university students. Journal of the East Asian Society of Dietary Life, 23: 681-689, 2013.

Kim JH, Lee MJ, Yang IS, Moon SJ. Analysis of factors affecting Korean eating behavior. Journal of the Korean Society of Food Culture, 7: 1-8, 1992.

Kim MJ, Kim KH, Kim H. A study on nutrition knowledge, dietary habits and lifestyle of male and female university students in Deajeon. Korean Journal of Human Ecology, 22: 701-709, 2013.

Kim MK, Lee GC. Weight reduction dieting survey and satisfaction degree and diet related knowledge among adult women by age. Journal of the Korean Society of Food Science and Nutrition, 35: 572-582, 2006.

Kim YJ, Moon JA, Wang SG. A study on diet \& food habits in college student. Natural Science, 21: 117-128, 2010.

KOSIS (Ministry of Health, Welfare and Family Affairs, Obesity prevalence: sex, 19 years old and above). 2016.12.27.

Lee MS, Kwak CS. The comparison in daily intake of nutrients, quality of diets and dietary habits between male and female college students in Daejeon. Korean
Journal of Community Nutrition, 11: 39-51, 2006.

Lee MS. Dietary behavior factors for desirable nutrient intakes of the oldest-old population in Sunchang county. Korean Journal of Community Nutrition, 14: 699-709, 2009.

Lee SM, Yoon J, Jeong HS. Effects of health diet lifestyle and health improvement motivation on the healingexperience demand. Korean Journal of Food and Cookery Science, 31: 413-422, 2015.

Lim HJ, Park HR, Ku HG. A study on the obesity situation of youth and children and policy measures. National Youth Policy Institute, Sejong, p157, 2009.

Ministry of Culture, Sports and Tourism. 2013 Survey on citizen's sports participation. Ministry of Culture, Sports and Tourism, Sejong, p75, 2012.

Na MS, Jang KY. Women's diet experience and its relation with self respect. Asian Journal of Beauty and Cosmetology, 5: 167-185, 2007.

Na MS, Jang KY, Kim, MH. Women's diet experience and its relation with stress. Asian Journal of Beauty and Cosmetology, 6: 39-61, 2008.

Oh YK, Hwang SY. Effects of obesity on survival rate and disease-free survival rate of breast cancer patients sub-classified according to reproductive history and age. Journal of Korea Academia-Industrial cooperation Society, 18: 105-114, 2017.

Park HS, Kwon SJ. The differences in the knowledge of cancer causes, and preventive health behaviors of college students. Korean Journal of Security and Safety, 8: 85-104, 2012.

Park JY, You JS, Chang KJ. Dietary taurine intake, nutrients intake, dietary habits and life stress by depression in Korean female college students: a case-control study. Journal of Biomedical Science, 17: S40, 2010.

Protani M, Coory M, Martin JH. Effect of obesity on survival of women with breast cancer: systematic review and metaanalysis. Breast Cancer Research and Treatment, 123: 627-635, 2010.

Rock CL, Doyle C, Demark-Wahnefried W, Meyerhardt J, Courneya KS, Schwartz AL, Bandera EV, Hamilton KK, Grant B, McCullough $\mathrm{M}$, et al. Nutrition and physical activity guidelines for cancer survivors. CA: $A$ Cancer Journal for Clinicians, 62: 243-274, 2012.

Seo JS, Park HA, Kang JH, Kim KW, Cho YG, Hur YI, Park YR. 
Obesity and obesity-related lifestyles of Korean breast cancer survivors. Korean Journal of Health Promotion, 14: 93-102, 2014.

Sim EK, Lee SR. Beauty \& nutrition. Chunggu Pubilshing, Seoul, p143, 2015.

Stice E, Shaw HE. Role of body dissatisfaction in the onset and maintenance of eating pathology: a synthesis of research findings. Journal of Psychosomatic Research,
53: 985-993, 2002.

Yim KS. Commercial obesity management program. Korean Journal of Community Nutrition, 8: 424-432, 2003.

Yoo SL, Lee S. Barriers to physical activity from obesity management perspective of children and adolescents from low income family. Korean Journal of Sport Psychology, 28: 45-58, 2017. 


\section{국문초록}

\section{0대 남녀 대학생의 다이어트 지식, 태도 및 동기가 식습관에 미치는 영향}

김솔아, 심은경*

동명대학교 뷰티케어학과, 부산, 한국

목적: 본 연구에서는 20 대 남녀 대학생의 다이어트 지식, 태도 및 동기가 식습관에 미치는 영향을 살펴보고자 한다. 이를 통해 대학 생들의 올바른 식습관 형성과 건강한 생활을 유지할 수 있도록 도움을 주는데 목적이 있다. 또한 영양 관련 교육 프로그램의 기초자 료로 제공하고자 한다. 방법: 경상남도, 부산, 서울 지역의 20대 남녀 대학생을 대상으로 다이어트 지식, 태도, 동기 및 식습관을 알 아보기 위하여 자기 기입식 설문지를 사용하였다. 회수된 설문지 최종 267 부를 분석하였다. 결과: 다이어트 지식 수준이 높은 그룹 은 다이어트 관심도가 높았고 미디어를 통해 정보를 얻으며, 실패원인을 의지력 부족과 잘못된 식습관이라고 응답하였다. 공통적으 로 다이어트 태도 수준과 동기가 통계적으로 유의하게 높은 그룹은 다이어트 지출비용을 10 만원 이상 사용하며, 관심도가 높고 미 디어를 통해 정보를 얻는 그룹이었다. 식습관에서는 다이어트 정보를 미디어, 주변 사람들, 다이어트 관련 전문기관이라고 응답한 그룹이 유의하게 식습관이 좋은 것으로 나타났다. 또한, 다이어트 태도와 다이어트 동기는 정(+)의 상관관계를 보였다( $p\langle 0.01)$. 식 습관에는 다이어트 태도가 다이어트 동기, 지식보다 더 유의한 관련성을 보였다 $(p<0.01)$. 결론: 다이어트 지식은 식습관에 영향을 미치지 않았으며 다이어트에 대한 태도 수준과 다이어트 동기가 높을수록 좋은 식습관을 가진다고 조사되었다.

핵심어: 다이어트 지식, 태도, 동기, 식습관, 대학생

\section{참고문헌}

강지은, 최한석, 최지호, 정석태, 여수환, 김미향. 음주 여부에 따른 남녀 대학생의 식습관 비교 연구. 동아시아식생활학회지, 23: 681-689, 2013.

김명경, 이귀주. 연령별 성인 여성의 체중감량 다이어트 실태와 만족도 및 관련지식. 한국식품영양과학회지, $35: 572-582$, 2006.

김미자, 김기혁, 김혜영. 대전지역 남녀 대학생의 영양지식, 식습관, 생활습관 비교 연구. 한국생활과학회지, 22: 701-709, 2013.

김연정, 문진아, 왕수경. 대학생들의 다이어트 식습관 실태 조사. 자연과학, 21: 117-128, 2010.

김정현, 이민준, 양일선, 문수재. 한국인의 식행동에 영향을 주는 요인 분석. 한국식생활문화학회지, 7: 1-8, 1992.

나명순, 장강연. 여성들의 다이어트 경험과 자기존중감과의 관련성. 아시안뷰티화장품학술지, 5: 167-185, 2007.

나명순, 장강연, 김미혜. 여성들의 다이어트 경험과 스트레스와의 관련성. 아시안뷰티화장품학술지, 6: 39-61, 2008.

문화체육관광부. 2013 국민생활체육참여실태조사. 문화체육관광부, 세종, p75, 2012.

박혜선, 권순정. 대학생의 암 발병원인에 대한 지식 및 예방적 건강행위의 차이. 한국사회안전학회지, 8: 85-104, 2012.

심은경, 이순례. 미용영양학. 청구문화사, 서울, $\mathrm{p} 143,2015$.

안민윤, 이중재, 오현숙, 임형호. 대학생 건강검진 수검자의 BMI, 혈액인자, 생활습관이 비만관련 삶의 질에 미치는 영향. 한 방재활의학과학회지, 24: 71-82, 2014.

오영경, 황선영. 출산력과 연령으로 그룹화한 유방암 환자에서 비만이 생존율 및 무병생존율에 미치는 영향. 한국산학기술학

회논문지, 18: 105-114, 2017.

유생열, 이슬. 저소득층 아동 - 청소년의 비만 관리 관점에서 본 신체활동 장애요인. 한국스포츠심리학회지, 28: 45-58, 2017.

이미숙, 곽충실. 대전지역 일부 대학생의 영양소 섭취 상태, 식사의 질과 식습관에 있어서 남녀의 차이에 관한 연구. 대한지역 
사회영양학회지, 11: 39-51, 2006.

이미숙. 순창군 장수인의 영양소 섭취수준에 영향을 미치는 식행동 인자. 대한지역사회영양학회지, 14: 699-709, 2009.

이상민, 윤지영, 정희선. 건강식생활 유형 및 건강증진 동기가 힐링체험 욕구에 미치는 영향. 한국식품조리과학회지, 31 :

413-422, 2015.

임경숙. 상업성 비만관리프로그램의 현황. 대한지역사회영양학회지, 8: 424-432, 2003.

임희진, 박형란, 구현경. 아동 · 청소년 비만 실태 및 정책방안 연구. 한국청소년정책연구원, 세종, $\mathrm{p} 157,2009$.

정덕조. 대학생들의 비만인식, 식습관 태도 및 체중조절행위 실태 조사. 과학과 문화, 1: 1-8, 2004.

정영호, 고숙자, 임희진. 청소년 비만의 사회경제적 비용. 보건사회연구, 30: 195-219, 2010.

주병하. 고등학생들의 건강지식 이해수준과 건강행동 실천 관계분석. 한국웰니스학회지, 12: 475-487, 2017.

최은옥, 우경자, 천종희. 인천에 거주하는 여성의 다이어트에 대한 인식과 지식. 한국식생활문화학회지, 14: 225-231, 1999. 최재규, 신미경, 서은숙. 익산지역 대학생의 체형인식과 거주형태에 따른 식습관 비교. 한국생활과학회지, 13: 97-110, 2004.

최정은, 김영국. 대학생들의 영양 지식 식이 자기효능감 및 식습관과 메뉴선택행동과의 관계. 외식경영연구, 15: 249-275, 2012.

최주연, 류상희. 식생활 교육 프로그램이 초등학교 아동의 영양지식과 식습관에 미치는 영향. 한국실과교육학회지, 23: 319334, 2010.

한명주, 조현아. 서울지역 대학생의 식습관과 스트레스정도에 관한 조사. 한국식생활문화학회지, 13: 317-326, 1998. KOSIS (질병관리본부, 비만 유병률 추이: 성별, 만 19세 이상), 2016.12.27. 


\section{中文摘要}

\section{减肥知识、态度和动机对20多岁男女大学生饮食习惯的影响}

金全아, 沈恩慶 ${ }^{*}$

东明大学美容学科, 釜山, 韩国

目的: 探讨减肥知识、态度和动机对20多岁男女大学生饮食习惯的影响。目标是帮助他们养成正确的饮食习惯, 保持健 康的生活方式。另外, 本文旨在为营养相关项目提供基础数据。方法: 对庆尚南道、釜山、首尔地区的20多岁男女大学 生, 为调查他们的减肥知识、态度、动机和饮食习惯, 进行了自填式问卷调查, 总共分析了267份问卷。结果: 减肥相关 知识水平高的群体对减肥高度感兴趣, 通过大众媒体收到有关减肥的信息, 并指出减肥失败的原因是缺乏意志力和错误 的饮食习惯。减肥态度和动机明显高的群体的共同点是减肥支出费用达到10万元韩币以上, 以及对减肥高度感兴趣, 并 通过媒体获得信息。饮食习惯而言, 通过大众传媒、熟人、体重相关组织获得减肥信息的群体表现出良好的饮食习惯, 具有统计学意义。另外, 减肥态度与动机呈正相关 $(p<0.01)$ 。就饮食习惯而言, 减肥态度比减肥动机和减肥知识更具 有相关性 $(p<0.01)$ 。结论: 通过以上研究结果, 减肥知识对饮食习惯没有影响, 随着减肥态度和动机的增加, 观察到更 好的饮食习惯。

关键词: 减肥知识, 态度, 动机, 饮食习惯, 大学生 